\title{
The SSRI Trials in Children: Disturbing Implications for Academic Medicine
}

\author{
Jonathan Leo, PhD \\ Parrish, FL
}

\begin{abstract}
The recent announcement by the Food and Drug Administration (FDA) requiring pharmaceutical companies to warn patients about the increased likelihood of suicidal thoughts when taking antidepressants was largely due to the recent availability of data that had gone unreported in the original research reports. The current article is a summary of the comparison between the published literature and the recently released data available on the FDA web site, with a focus on Prozac, Paxil, and Zoloft. The discrepancies between the two versions suggest that the scientific community was not given enough information in the published medical literature to make adequately informed decisions about the optimal method for treating emotionally distressed children. There are many voices that want to blame the FDA for its role in the widespread use of these medications. The current article focuses on the role that academic medicine, played in the process whereby these medications became so widely accepted.
\end{abstract}

Keywords: SSRI; suicide; pediatric depression; FDA

C6 Onfusion, manipulation, and institutional failure" was the recent summary on The Lancet's editorial page about the research into selective serotonin reuptake inhibitor (SSRI) use in childhood depression (Editors, 2004). The editors' conclusions were based on revelations that pharmaceutical companies had selectively reported favorable research about the use of antidepressants in children. However, the medical community makes a mistake if it believes that the current problem is just one of unpublished data, which the pharmaceutical companies have kept hidden. If it were only as straightforward as a relatively few acts of corporate irresponsibility, then the solution would be fairly simple, but virtually everyone knows it is more complicated. The SSRIs are not the only drugs involved and, moreover, the pharmaceutical companies are not the only players involved. The more important problem is that for 10 years the system of academic medicine failed to the point that the academic journals were circulating a myth about the benefits of psychotropic drugs for children that had little to do with the truth. 


\section{BACKGROUND}

\section{Marketing Antidepressants}

In October 2004, the Food and Drug Administration (FDA) announced that commonly used antidepressants likely lead to an increase in suicidal thoughts or actions in some children and teens; they also announced that the same problem might exist for adults. Almost 1 year prior to this, the Medicines and Healthcare products Regulatory Agency (MHRA), the British equivalent of the FDA, effectively banned the use of these drugs, except for Prozac, in children and adolescents under 18 years of age. Ten years ago, the market for antidepressants in children was practically nonexistent, 5 years ago it was booming, and now, it seems to be in jeopardy. Considering how much money we have spent over the past decade on the search for the causes and treatment of mental anguish, who would have thought we would end up with a warning label saying that these drugs might lead to an increased rate of suicide?

In the late 1980s, adults started to use the selective serotonin reuptake inhibitors (SSRIs) for depression, and since then the brand names, such as Prozac, Paxil, and Zoloft, have become household names. Indeed, three of the seven most commonly used drugs are now mood elevators. By the early 1990s, it didn't matter that they were not officially approved for use in children: they were commonly given to children as young as 6 years old. In some cases prescriptions were written for infants under twelve months (Grinfeld, 1998).

Although you would never know it from a perusal of the mainstream psychiatry journals over the last decade, when the SSRIs first came on the market in the late 1980s there were hints of increased suicidality in people taking the drugs (Healy, 2003a). It is not surprising that some psychologically distressed people commit suicide; after all, a distressed state is a predisposing factor for suicide. So, naturally, to accusations that the drugs cause some people to take their own lives, the companies' response has always been: It's the disease, not the drug. While it may seem hard to disentangle the role of these two variables, the disease and the drug, there is a way, and it has been done. The place to begin is with the companies' own efficacy studies.

These studies started with a group of depressed patients, which was divided in half. Half the group was given a drug, and the other half a placebo. According to the FDA data, there was an increase in suicidality in the drug-exposed group. Furthermore, this is not an isolated finding, but is the case for almost every single antidepressant studied-in adults, no less (Healy, 2003b). No longer can we simply blame the disease: the drugs appear to be playing a role in making some people more likely to take their lives.

In the late 1990s, the first major scientific papers investigating the use of these drugs in children, funded by the drug companies, started to appear in the medical literature. The studies made a case for these drugs as being safe and effective for the treatment of childhood distress. The studies subsequently became part of the companies' submissions to the FDA to get the drugs approved for children.

However, drug companies do not just supply the FDA with references to published papers, they supply significantly more detail than what is available in the scientific papers. The version submitted to the FDA is not available immediately to the public, but, eventually, some of the data finds its way onto the FDA web site, or becomes available due to court proceedings. Only when all the data is in the public realm can a comparison 
between the two versions be made: the one published in the medical literature and the unpublished account submitted to the FDA. It was this embarrassing mismatch between the published and unpublished data that forced the FDA to step back into the fray.

To win approval of a drug, for a given condition, in a certain population, a drug company must submit two positive studies to the FDA. To obtain its two positive studies, the company might do five, six, or as many as ten studies. Even if the majority of the studies are negative, as long as two are positive the drug can be awarded FDA approval. For any given study, the basic idea is that the benefits should outweigh the risks. It is taken for granted that every drug will cause some sort of side effects, but if they are minimal and the benefits are significant, then the FDA, the medical community, and the patients all agree to live with the risks. Out of seven requests to the FDA for approval of a specific antidepressant to treat childhood depression (Prozac, Paxil, Zoloft, Celexa, Remeron, Effexor, Serzone), Prozac was the only drug that was approved. While not approved for the treatment of depression, Zoloft was approved for the treatment of Obsessive Compulsive Disorder (OCD) in children.

In terms of benefits, the researchers need to show that patients treated with the drug do significantly better than patients treated with a placebo. If the FDA decides that the benefits outweigh the risks then the drug is officially approved. Importantly, once a drug is approved, for, perhaps, depression in adults, there is nothing stopping doctors from prescribing the drug to other groups of people- to children, for instance. Nor is there anything to keep doctors from prescribing the drug for other psychiatric conditions, such as, Oppositional Defiant Disorder (ODD). Although Prozac was not approved for children until 2003, it was perfectly legal for doctors to prescribe it, off-label, to children prior to official FDA approval. Likewise, even though the other SSRIs are still not approved for use in children, it is perfectly legal to use them.

In fact, the child psychiatry profession fully endorsed the use of these drugs well before the FDA approved them, and, in an even odder twist, the profession endorsed the use of them well before any of the major studies in children were even published (Koplewicz, 1997). It appears that one reason for doing the studies in the first place was to justify already well-accepted prescribing patterns. If a trend is created "because everyone else is doing it" then it appears that the child psychiatry profession's use of these drugs in the late 1990s more closely resembled a trend instead of a logical scientific undertaking.

How did all this happen? Naturally, there are no easy answers, but, as a start, one needs to look at the studies asserting that these drugs are safe and effective. In the following discussion, the papers written for the scientific community are compared to the FDA documents (Mosholder, 2004). For the most part, the field consists of about 12 papers, spanning almost a decade, which, when stacked together, fit nicely into a three-ring binder. The studies involving the three most common selective serotonin reuptake inhibitors (SSRIs) Prozac, Paxil, and Zoloft - serve as excellent examples of how, at every step of the way, the benefits were overestimated and the risks underestimated. According to Healy, "There is probably no other area of medicine in which the academic literature is so at odds with the raw data" (Healy, 2004, p. 10). On one hand, debating the details from any one study, about how one or two children's side effects should be categorized, might seem trivial. On the other hand, when the literature on the use of antidepressants in children is looked at as a complete body of work there is a problematic track record, which is anything but trivial. 


\section{STUDIES SUBMITTED FOR FDA EVALUATION}

\section{Prozac (Fluoxetine)}

The lead author of the two studies submitted to the FDA as part of Eli Lilly's successful request to get Prozac approved for children was Graham Emslie, a professor at The University of Texas Southwestern Medical Center at Dallas. The first study, funded by the National Institute of Mental Health (NIMH) and published in 1997, reported that "side effects, as a reason for discontinuation, were minimal" (Emslie et al., 1997, p. 1033). There is no mention in the paper about any children attempting suicide. However, in the FDA's "Medical Review of Prozac," written in 2001 but not made public until 2003, there is a discussion about two children on Prozac attempting suicide (Center for Drug Evaluation and Research, 2001; Leo, 2004). Thus, between 1997 and 2003, doctors reading the published paper and trying to decide if Prozac should be used in children were not given all the information. Even by 2003, only those doctors who regularly peruse the FDA web site would have known about the two suicide attempts in the group of 48 Prozac-treated patients.

Under government pressure, the drug companies have released their unpublished data, while NIMH has still not explained the discrepancy between its own published and unpublished versions of the first Prozac for children paper. Also unclear are the details of how the data from this NIMH study became part of Eli Lilly's package that was submitted to the FDA for the evaluation of whether or not Prozac should be used in children. There is nothing wrong with Lilly simply using data in the public realm, but the data Lilly submitted to the FDA went beyond what was in the public realm, that is, the two attempted suicides. Eli Lilly's access to NIMH's unpublished data suggests a close relationship between NIMH and the drug companies. The obvious question is: Did Lilly pay NIMH or the researchers for data that was the product of a taxpayer-funded research project? Regardless of the monetary questions surrounding the first Prozac study, by the time the second Prozac study was published in 2002, Emslie and his coauthors were either Lilly employees or paid consultants. And now, as of 2004, Emslie is still receiving money from NIMH to continue investigating these medicines in children.

When an investigator is simultaneously receiving funds from a nonprofit institution and a for-profit company-one organization primarily committed to finding the truth, and one organization primarily committed to satisfying shareholders-it has to be extremely difficult to keep these allegiances straight. When a professor in this situation, at a scientific symposium for instance, claims that "Studies show ..." is the professor referring to the published studies, or all the studies? As we are seeing, this qualifier has now become one of the essential pieces of information that goes into evaluating a scientific claim.

What is clear, though, is that, in general, all these studies are designed to give the drug the best chance of coming out ahead. For instance, the two Prozac studies, and several of the others, included a placebo washout phase, which involved putting all the patients on a placebo for a specified time period and then dropping those patients that improved. In the first Prozac study, 10 children were dropped from the study during the placebo washout.

The second Prozac study also had a unique twist, which consisted of a run-in phase to preselect for drug responders (Dubitsky, 2004; Emslie et al., 2002). All the Prozac-treated children in this study were given $10 \mathrm{mg}$ for the first week, and children who did not respond, or who had negative responses, could then be dropped from the study (p. 1206). At the start of week 2, the dose was increased to $20 \mathrm{mg}$. The subsequent statistical analysis only used children who had had at least one week of treatment with $20 \mathrm{mg}$ (p. 1208). Thus, 
before the study even started, there was a mechanism in place to maximize any difference between the drug and placebo groups - the placebo group was preselected for nonresponders, while the drug group was preselected for responders. Yet even with this advantage, for the prospectively defined primary outcome measure, $65 \%$ of the children on Prozac had a beneficial response compared to $53 \%$ of the placebo patients, a result that was not statistically significant. It was only by looking at other measures that clinical significance was found; on the patient- and parent-rated scales there was no advantage to Prozac, but on one of the clinician-rated scales there was a slight advantage to Prozac. Although Russell Katz of the FDA wrote, "one could argue that this post hoc choice of primary outcome is inappropriate," the FDA accepted the post hoc change and approved Prozac for children in January 2003 (Center for Drug Evaluation and Research, 2002, p. 13). It was the only antidepressant that the FDA ever approved for use in childhood depression.

In 2003, when the British MHRA banned the use of these medications in children and teens, Prozac was spared. Not because the suicide profile was noticeably different, but because Prozac appears to offer more benefit than its competitors (although even these points are open to debate). Yet, according to the data, the efficacy of Prozac is not very significant. Using the researchers' own criteria for defining an "improvement," and taking into account the large placebo effect, for every ten children it is given to, it maybe helps one patient.

\section{Paxil (Paroxetine)}

In 2001 The Journal of the American Academy of Child and Adolescent Psychiatry published a study that found that Paxil was appropriate for the treatment of emotional distress in children. The paper, authored by the leaders of the child psychiatry profession, concluded that, "Paroxetine is generally well tolerated and effective for major depression in adolescents" (Keller et al., 2001, p. 762). At first, this paper seemed to justify the prescribing patterns of the past several years.

But, at the time the paper was published, it was clear to some people that there were major problems with the study (Jureidini \& Tonkin, 2003). First, the study provided little evidence that Paxil was better than placebo. For the primary endpoint, the difference between the Paxil-treated and placebo groups was not significant (Laughren, 2004, p. 5). Secondly, there were significant side effects in the Paxil-exposed children compared to those in the placebo group.

While the authors of the study vigorously defended their paper against the critics, problems arose when internal, confidential company documents surfaced, supporting the critics instead of the company's own paid experts. The memo, written in October 1998 and stamped, "For Internal Use Only," was a summary of the same Paxil study. It acknowledged that the study, at that point referred to as Protocol 329, had not demonstrated efficacy for Paxil and that "it would be commercially unacceptable to include a statement that efficacy had not been demonstrated, as this would undermine the profile of paroxetine" (GlaxoSmithKline, 1998).

In the published account of Protocol 329, the authors included an extensive list of 32 side effects such as nausea, vomiting, chest pain, and so forth. Although, ever since the SSRIs were approved for adults, there has been the suspicion that they lead to increased thoughts of suicide (Healy, 2003b), there is no mention of any children having any suicidal thoughts or attempting suicide in the published version of Protocol 329. Interestingly, six of the children on Paxil had "emotional lability." In reality, some of these "emotionally labile" children actually had suicidal thoughts (Healy 2004). At the urging of the British 
government, GlaxoSmithKline acknowledged that in Protocol 329's Paxil-treated group, there were 5 children out of 93 who had suicidal thoughts; in the placebo group none of the 89 children had suicidal thoughts. Prior to this revelation the average physician would have been left completely ignorant of this vital statistic.

The investigative news show Prime Time Live recently broadcast a segment about GlaxoSmithKline distributing a memo (different than the one mentioned above) to its sales force touting Paxil's, "remarkable efficacy and safety in the treatment of adolescent depression" in 2001, at a time when the company was fully aware that there were problems with Paxil (ABC, 2004). But far more problematic for the medical community than a sales force being given a slanted view from sales managers is that doctors were given the same slanted view in medical journals from scientists. If the company is at fault for concealing data from its sales force, then what about the scientists who wrote the papers? Whether you believe it was the pharmaceutical salespeople or the medical school professors who convinced clinicians to use these medicines, probably says a lot about your views of medicine in general. Shouldn't the media's focus really be on the journals, not the marketing memos?

It would be interesting to know the timeline of events, and the nature of the scientists' involvement with the Paxil study. For instance, at what point did the stated authors of the Paxil study even become involved with the project? Were they involved by 1998, when the company memo acknowledging the problems with the study was written, or did they join the project after the actual data was collected? If they were involved by 1998, and were aware of the results, then how do they defend their involvement in a paper whose stated "target" was "to effectively manage the dissemination of these data in order to minimize any potential negative impact"? When they published their paper, were they aware of negative data?

\section{Zoloft (Sertraline)}

At the end of 1996, Pfizer submitted a request to the FDA for the approval of Zoloft as a treatment for Obsessive Compulsive Disorder (OCD) in children, and in October 1997 the FDA approved the request (Center for Drug Evaluation and Research, 1997). According to Healy, anyone reading the published literature on the use of Zoloft in children at that time would have learned of one suicidal act in a Zoloft-treated child in Pfizer's studies. Yet in the FDA's evaluation of the data up to that point, there were six instances of suicidal acts in children taking Zoloft (Center for Drug Evaluation and Research, 1997; Healy, 2004). Why the discrepancy between the published and unpublished data? The explanations are interesting. In one paper by Alderman and his colleagues, the authors decided to only publish side effects that occurred in $10 \%$ or more of the patients, which excused them from reporting the fact that $9 \%$ of the children on Zoloft in their study had engaged in a suicidal act (Alderman, Wolkow, Chung, \& Johnston, 1998; Healy, 2003a).

In August of 2003, a major paper was published in The Journal of the American Medical Association, stating that Zoloft "is an effective and well-tolerated short-term treatment for children and adolescents with Major Depressive Disorder" (Wagner et al., 2003, p. 1033). For this article, the authors combined the results of two smaller studies and collectively presented the findings. Karen Wagner, the lead author, was also an author of some of the Paxil and Prozac studies in children.

It might seem odd that a company-sponsored paper would combine two studies into one paper. Publishing two positive papers would certainly seem to make a stronger case for the 
drug. After all, the headline, "Two Studies Show ..., , or better yet, "Multiple Studies Show ..." sounds much more convincing than "One Study Has Shown ..." So why did the authors combine the two studies? It likely had something to do with the fact that, as stand-alone studies, one was a failure and one showed only a trend. Only by combining the two studies as one could statistical significance be reached.

Just as in the studies with Paxil and Prozac, doctors trying to weigh the pros and cons of prescribing these drugs were not given all the information in the medical literature; only by reading government reports (Committee on Safety of Medicines, 2004) would doctors have known that, individually, each trial was a failure. The headline could just as easily have been "Two Studies Show That Zoloft Should Not Be Used in Children."

After combining the two studies, of the children in the Zoloft group, $69 \%$ had a successful response, whereas $59 \%$ of the children in the placebo group experienced a successful response: not a large difference, but enough to make the headlines. Clearly, the marketing department was successful in its management of the negative information surrounding this study.

There is also an interesting nuance to their experimental design. The authors do not mention how many of the patients in this study had a history of psychiatric medication, but since they were outpatients, probably most of them had a history of SSRI treatment. One of the exclusion criteria for entry into this study was a "history of failure to respond to a clinically adequate dosing regiment of an SSRI." In other words, those who have not responded to prior SSRI treatment were excluded, but it seems that another way to word this would be: "Our study, designed to determine if SSRI treatment successfully treats depression, will only use those children who have been successfully treated with an SSRI for depression." In addition, 17 of the Zoloft-treated children, compared to 5 placebo-treated children, dropped out because of serious adverse events.

According to the FDA report, in these two studies there were six suicide events in the Zoloft group and two in the placebo group. However, in the published paper it is not quite as clear. Regarding suicides, in one part of the paper the authors reported, "the number of suicide attempts was the same in each treatment group ( 2 for sertraline [Zoloft] and 2 for placebo)" (p. 1039). At least, this was the quote the press picked up on (Burton \& Callahan, 2003). However, in another part of the paper, the authors also mention that in terms of suicidal ideation there were three events in the Zoloft group versus none in the placebo group. In addition, one Zoloft patient had an "aggressive reaction." This description of events did not make the press, or receive much attention from the authors, but it did receive attention from the regulators.

One defense of the paper's roundabout way of discussing the suicides might be that when the studies were being conducted, the suicide issue was not on the radar so it was overlooked. Only with the benefit of hindsight, once the issue of suicidality was raised, did a retrospective look at this study point to increased suicidality. The problem with this defense is that, by the time the Zoloft study was published, there were numerous hints about a link between the SSRIs and suicides in children. Even the authors acknowledge in the paper that regulators in the United States and United Kingdom are looking at the suicide issue (p. 1038), yet they still sidestep the suicide data in their own study.

It is surprising that the peer reviewers of the Zoloft study did not think to ask more questions about the study, such as:

1. Why not mention the findings of each study individually in the paper?

2. What about the discrepancy between the withdrawal rates of the Zoloft and placebo groups?

3. What about only a $10 \%$ difference between the drug and placebo groups? 
One of the investigators involved with the Zoloft study, who was not an author and, apparently, not privy to drafts of the paper, eventually wrote a letter to JAMA after the study was published, pointing out some of the very concerns that the reviewers should have spotted. Though the letter unfortunately went unpublished, it stated that the conclusions of the paper should have been: "Sertraline is ineffective when compared to placebo and is associated with increased adverse events" (Garland, 2004).

\section{THE AMERICAN COLLEGE OF NEUROPSYCHOPHARMACOLOGY'S RESPONSE}

As the child psychiatry profession was in the midst of a public relations problem, the American College of Neuropsychopharmacology published its Preliminary Report of the Task Force on Suicidal Behavior in Youth. The task force members claimed that, "there is sufficient evidence to conclude that, overall, SSRIs are effective in treating depression in children and adolescents" (American College of Neuropsychopharmacology, 2004, p. 4). The task force was composed of ten members who were pivotal in the medical community's acceptance of treating young children with these drugs. Three of the members, Graham Emslie, Karen Wagner, and Neal Ryan, were authors of the Prozac, Zoloft, and Paxil studies mentioned above. In light of the fact that the papers these authors wrote are the source of all the confusion, it is difficult to know how to characterize their following statement, "all data held by FDA or pharmaceutical companies should be made rapidly available to allow ACNP and other research organizations to conduct an independent evaluation of the risks and benefits of SSRIs" (p. 11). Their call for openness seems hollow when one considers the way the results from their own papers were reported.

The ANCP has declared that, based on their analysis of confidential data, there is no link between suicide and SSRIs; and while they cannot share all the data with the scientific community, because of their credentials, we should trust their analysis - conflicts of interest aside. Yet, this is not the way science functions.

\section{TWO PAPERS FROM THE UNITED KINGDOM}

In the spring of 2004, two papers, which brought worldwide attention to the issue, were published in British medical journals, not American journals. This turn of events was hardly surprising since at every step of the way the British medical community had shown more skepticism. The first paper, published in the April 2004 issue of The British Medical Journal (BMJ), was a review of the SSRIs for children by Jon Jureidini and his colleagues (Jureidini et al., 2004). They concluded that the authors of the original papers had exaggerated the benefits and downplayed the risks. The paper, whose importance cannot be underestimated, received a tremendous amount of media coverage. Yet, Jureidini did not really uncover any new data, nor did he find some "smoking-gun" hidden away in a drug company basement. He and his coauthors summarized the data that the original authors had mentioned in their studies, and their message was clear: Before the use of these drugs becomes too entrenched, it is time to pause and take another look at the scientific evidence. For instance, the original authors of the Zoloft paper thought that a 10\% difference between the Zoloft and placebo group was significant, but, as the Jureidini paper pointed out, or reminded 
people, this statistic is not very clinically significant. The problem for academic medicine is that when the entire issue is approached as a rational scientific enterprise, where the data drives the treatment decisions - rather than what appears to have been occurring where the decision to prescribe these drugs occurred well before the data was even published-then it is clear that there is little justification for the current prescribing patterns.

Two weeks later, The Lancet published a review by Whittington and colleagues that brought even more attention to the controversy (Whittington et al., 2004). These authors showed that once the unpublished literature is included in the risk-benefit analysis of these drugs, the benefits do not outweigh the risks. With the publication of the Jureidini and Whittington papers in mainstream medical journals, the SSRIs were in more trouble. The editorial in The Lancet following the Whittington paper could not have been clearer:

That such an event [suicide] could be precipitated by a supposedly beneficial drug is a catastrophe. The idea of that drug's use being based on selective reporting of favourable research should be unimaginable ... (Editors, 2004, p. 1335)

What seems to bother The Lancet editors, and others, is that, as a body of research, there seems to be a systematic bias toward downplaying the suicide issue. Whether there is a link between suicide and the antidepressants, and whether there is significant benefit to the antidepressants are still valid scientific questions, which will eventually be answered. However, so far, the manner in which the academic community has handled the data calls into question who will now investigate these issues. The next time one of these papers is published, the logical question on many people's minds will be: What about the unpublished studies?

Of course, the drug companies and authors of these studies will argue about the data mentioned in this paper (Clary, 2004), but, whatever the arguments, the data were incriminating enough to convince two governments to intercede; the Americans with a warning label, and the British with an outright ban on several of the medications for people under 18 years of age.

However, besides concerns about suicide, there is a very good reason for not taking the drugs: They simply don't work very well. Even in the adult studies, the difference between the percentages of favorable responses in the drug-treated group compared to favorable responses in the placebo group is minimal (Kirsch, Moore, Scoboria, \& Nicholls, 2002). In the risk-benefit analysis, given such little benefit, there is little justification for putting up with the suicide risk. If the studies had shown significant benefits, the suicide risk would have been better tolerated by the regulatory agencies.

\section{BOOK CHAPTERS}

In addition to journal articles, textbook presentations are another area where clinicians have apparently not been given all the information that they need to make a decision about suicidality and the SSRIs. During the 1994 Wesbecker v. Eli Lilly trial, Gary Tollefson, the head of neuroscience at Eli Lilly and a co-author of a textbook chapter on the SSRIs, stated, "there is absolutely no medically sound evidence of an association between any antidepressant medicine, including Prozac, and the induction of suicidal ideation or violence" (Zuckoff, 2000). But since the Wesbecker trial, several articles in newspapers and medical journals have suggested that there was information available to Tollefson when he made this statement. 
In 2005, an article in the BMJ by Jeanne Lenzer discussed recent documents supposedly showing that Eli Lilly knew about a potential link between suicidality and the SSRIs as early as the 1980s, and that these documents were kept from the plaintiffs in the Wesbecker trial (Lenzer, 2005). According to the BMJ article, an internal report of November 8, 1988, found that in clinical trials $38 \%$ of fluoxetine-treated patients reported new activation compared to only $19 \%$ of the placebo-treated patients. The documents, written by employees at Lilly, and pointing to a potential link between suicide and Prozac, now appear to cast doubt on Tollefson's testimony during the Wesbecker trial.

Lilly was not pleased with the BMJ article and disputed the claim that pertinent documents were withheld from the plaintiffs. The BMJ subsequently issued a retraction and stated that the pertinent documents had been made available to the lawyers. However, the BMJ's apology did not discuss the veracity of the information contained in the documents (Editors, 2005).

In 2003, The New York Times raised the issue of Tollefson's candor at the 1991 FDA hearing on the link between SSRIs and suicide (Harris, 2003). As part of the approval process for a new medication, the FDA requires the company making such a request to release any information about the status of the approval process in other countries. According to The Times, under questioning from the FDA, Tollefson, who was a Lilly consultant at that point, did not mention that in 1987 the German regulators believed there was strong evidence suggesting that there was a link between Prozac and suicide. During a subsequent trial, he was asked about not mentioning this to the FDA and replied: "That was not the question that was asked so I did not answer that question."

In 2000, The Boston Globe cited numerous documents in Eli Lilly's possession prior to 1998 that suggested that there was a link between suicide and Prozac. Besides mentioning the issue with German regulators, The Globe also pointed out that:

Internal documents show that in 1990, Lilly scientists were pressured by company executives to alter records on physician experiences with Prozac, changing suicide attempts to "overdose" and suicidal thoughts to "depression."

A lack of forthrightness might be considered acceptable in the courtroom or in government hearings; this is not the issue, at least in this article. In the courtroom most people would not offer evidence unless they are asked about it. However, even though Lilly employees made the documents available to the FDA and the lawyers, it appears that the information was not given to the academic community.

Putting the court proceedings aside, in 1998 the American Psychiatric Press published its Textbook of Psychopharmacology, which has a chapter on the SSRIs written by Gary Tollefson and Jerrold Rosenbaum, who was a member of Lilly's premarketing advisory committee for Prozac. Regarding a potential link between serotonin and suicide, Tollefson and Rosenbaum have a brief discussion, and then in summary cite the findings from the American College of Neuropsychopharmacology, "that no evidence indicated that SSRIs triggered emergent suicidal ideation above base rates associated with depression" (Tollefson \& Rosenbaum, 1998).

Like Tollefson's statements during the Wesbecker trial, in his textbook chapter there is no mention about any of these documents from the early 1990s, nor the findings from the German regulators, nor the concerns of other Lilly departments. Certainly, one possibility is that the different departments at Lilly were not communicating, and that Tollefson and Rosenbaum never discussed the suicide issue with those employees at Lilly that did have concerns. However, in the Forsyth vs. Eli Lilly trial, Tollefson acknowledged that it was his 
access to the Lilly database that convinced him that there was no link between suicide and the SSRIs.

To further complicate the issue, in 1998 - the very same year that Tollefson and Rosenbaum's chapter was published-Eli Lilly was in the process of paying $\$ 20$ million for the patent on the R(-) isomer of fluoxetine, a more specific version of Prozac. The wording of the patent, "furthermore, fluoxetine produces a state of inner restlessness (akathisia), which is one of its more significant side effects" (Garnett, 2000).

In light of what was left out of the Tollefson and Rosenbaum chapter it is evident that clinicians need to be much more skeptical when reading medical textbooks. At this point in time, left unanswered for the academic community is: What is the purpose of a medical textbook? Most readers of a textbook chapter do not expect that textbook authors are withholding information because they weren't asked about it.

\section{WHAT ARE CLINICIANS SUPPOSED TO THINK?}

The problem for academic medicine is that the average doctor, who wants to make an evidence-based decision about the use of a certain treatment, should be able to turn to experiments published in the medical literature for guidance. Unfortunately, in the case of using psychotropic drugs in children, this is not possible.

Many people want to blame the FDA for the approval of antidepressant use in children, or for not withdrawing the drugs from the market sooner, but out of seven requests from pharmaceutical companies for FDA approval, the FDA rejected six drugs; the only antidepressant they approved for children was Prozac. But, while the FDA rejected six studies, the rest of the medical community accepted them. Another way of looking at this entire affair is that the FDA had to actively intercede only because of a systemic problem in academic medicine. The FDA did not just have to deal with the problematic side effect of a medication, it had to deal with a profession in denial. If academic medicine had been working correctly, the FDA's drastic step would not have been necessary. Not only has the psychiatric profession fought the FDA every step of the way-for the most part, it has still not acknowledged the problem (Koplewicz, 2004). Many of the SSRI defenders point out that in the clinical trials none of the children with suicidal thoughts actually committed suicide. However, it seems counterintuitive for these defenders to downplay the relevance of suicidal thoughts, when it is the presence of suicidal thoughts that supposedly justified writing the prescriptions in the first place.

Doctors accepted these drugs and prescribed them so willingly not because they were given free pens, free dinners, or even free trips. They put their trust in the drugs because they were backed by papers that were: written by professors at the major academic medical centers; approved by peer reviewers; published in the major medical journals; cited in review articles; discussed at meetings; defended by The American College of Neuropsychopharmacology; and, underlying everything, given NIMH's stamp of approval (National Institute of Mental Health, 2001). In short, these papers were the talk of the town. You can hardly fault the average physician for putting faith in them.

By now, virtually everyone involved in medicine is aware of the need to take a healthy dose of skepticism before reading pharmaceutical company brochures or when attending talks by pharmaceutical representatives. It is now evident that those doses of skepticism need to be taken, or maybe even increased, when reading academic publications. 


\section{REFERENCES}

ABC. (2004, December 9). Drug maker withheld paxil safety data. Prime Time Live [Television broadcast]. Retrieved September 2005 from http://a.abcnews.com/Health/story?id=311956\& page=1.

Alderman, J., Wolkow, R., Chung, M., \& Johnston, H. (1998). Sertraline treatment of children and adolescents with obsessive-compulsive disorder or depression: Pharmacokinetics, tolerability, and efficacy. Journal of Child and Adolescent Psychiatry, 37, 386-394.

American College of Neuropsychopharmacology. (2004). Executive summary: Preliminary report of the task force on SSRIs and suicidal behavior in youth. Available at www.acnp.org/exec_summary.pdf

Burton, T., \& Callahan, P. (2003, August 27). Antidepressant use for kids gains support. Wall Street Journal.

Center for Drug Evaluation and Research. (1997). Approval package for NDA 19839/S-017 and S-018. Medical review of sertraline hydrochloride. Washington, DC: Author.

Center for Drug Evaluation and Research. (2001). Application 18-936-SE-064. Medical review of fluoxetine. Washington, DC: Author.

Center for Drug Evaluation and Research. (2002). Application number 18-936/SE5-064. Administrative documents for fluoxetine. Washington, DC: Author.

Clary, C. M. (2004). Sertraline pediatric depression trial met highest standards of study design and reporting. British Medical Journal, 328-879.

Committee on Safety of Medicines. (2004). Selective serotonin reuptake inhibitors (SSRIs) —overview of regulatory status and CSM advice relating to major depressive disorder (MDD) in children and adolescents. Retrieved March 2004 from medicines.mhra.gov.uk/ourwork/monitorsafequalmed/ safetymessages/ssrioverviewclintrialdata_101203.htm.

Dubitsky, C. (2004). Review and evaluation of clinical data placebo-controlled antidepressant studies in pediatric patients. Food and Drug Administration. Retrieved July 2005 from http://www.fda.gov/ ohrms/dockets/ac/04/briefing/2004-4065b1-08-TAB06-Dubitsky-Review.pdf.

Editors. (2004). Depressing research. The Lancet, 363, 1335.

Editors. (2005). Eli Lilly: Correction and apology. British Medical Journal, 330, 211.

Emslie, G. J., Heiligenstein, J., Wagner, K. D., Hoog, S. L., Ernest, B. A., Brown, E., et al. (2002). Fluoxetine for acute treatment of depression in children and adolescents: A placebo-controlled, randomized clinical trial. Journal of American Academy of Child and Adolescent Psychiatry, 41, 1205-1215.

Emslie, G. J., Rush, A. J., Weinberg, W. A., Kowatch, R. A., Hughes, C. W., Carmody, T., et al. (1997). A double-blind, randomized, placebo-controlled trial of fluoxetine in children and adolescents with depression. Archives of General Psychiatry, 54, 1031-1037.

Garland, J. (2004). Letter to editor. Unpublished manuscript. Retrieved July 2005 from http://www.ahrp .org/infomail/04/01/09.php.

Garnett, L. (2000, May 7). Prozac revisited: As drug gets remade, concerns about suicide resurfaces. The Boston Globe, p. 1.

GlaxoSmithKline. (1998). Seraxat/Paxil adolescent depression: Position piece on the phase III clinical studies. Executive summary.

Grinfeld, J. (1998, March). Psychoactive medications and kids: New initiatives launched. Psychiatric Times, 69.

Harris, G. (2003, August 7). Debate resumes on the safety of depressions wonder drugs. The New York Times. Retrieved September 2005 from http:/query.nytimes.com/gst/fullpage.html?res= 9E0DE4DD1731F934A3575BC0A9659C8B63\&sec=health\&pagewanted=print.

Healy, D. (2003a). Let them eat Prozac. Toronto, Canada: James Lorimer \& Company.

Healy, D. (2003b). Lines of evidence on the risks of suicide with selective serotonin reuptake inhibitors. Psychotherapy and Psychosomatics, 72, 71-79.

Healy, D. (2004). Suicidal evidence not addressed by FDA. [Letter from David Healy to Peter J. Pitts, Associate Commissioner for external relations, Food and Drug Administration]. Unpublished manuscript. Retrieved July 2005 from http://www.ahrp.org/risks/healy/FDA0204.php. 
Jureidini, J. N., Doecke, C. J., Mansfield, P. R., Haby, M. M., Menkes, D. B., \& Tonkin, A. L. (2004). Efficacy and safety of antidepressants for children and adolescents. British Medical Journal, 328, 879-883.

Jureidini, J. N., \& Tonkin, A. L. (2003). Paroxetine in major depression. Journal of American Academy of Child and Adolescent Psychiatry, 42, 514.

Keller, M. B., Ryan, N. D., Strober, M., Klein, R., Kutcher, S. P., Birmaher, B., et al. (2001). Efficacy of paroxetine in the treatment of adolescent major depression: A randomized, controlled trial. Journal of American Academy of Child and Adolescent Psychiatry, 40, 762-772.

Kirsch, I., Moore, T. J., Scoboria, A., \& Nicholls, S. S. (2002). The Emperor's new drugs: An analysis of antidepressant medication data submitted to the US Food and Drug Administration. Prevention and Treatment. Retrieved July 2004 from http://www.alpha-stim.com/Information/ Technology/Research/Research_PDF/EmperorsNewDrugs.pdf.

Koplewicz, H. (1997). It's nobody's fault: New hope and help for difficult children and their parents. Location: Three Rivers Press.

Koplewicz, H. (2004). Misguided resistance to appropriate treatment for adolescent depression. Journal of Child and Adolescent Psychopharmacology, 14, 7.

Laughren, T. P. (2004, January 5). Background comments for February 2, 2004 meeting of the Psychopharmacological drugs advisory committee (PDAC) and pediatric subcommittee of the anti-infective drugs advisory committee [FDA memorandum].

Lenzer, J. (2005). FDA to review "missing” drug company documents. British Medical Journal, 330, 7.

Leo, J. (2004). NIMH guilty too? Psychiatric News, 39, 31.

Mosholder, A. D. (2004). Executive summary: Suicidality in pediatric clinical trials with paroxetine and other antidepressant drugs. Follow up to 9-4-03 consult. Retrieved July 2005 from http://psychrights.org/Research/Digest/AntiDepressants/Mosholder/MosholderReport.pdf.

National Institute of Mental Health. (2001). Let's talk about depression. NIH publication No. 01 4162.

Tollefson, G. D., \& Rosenbaum, J. F. (1998). Selective serotonin reuptake inhibitors. In A. F. Schatzberg \& C. B. Nemeroff (Eds.), The American psychiatric press textbook of psychopharmacology (2nd ed., pp. 219-238). Washington, DC: The American Psychiatric Press.

Wagner, K. D., Ambrosini, P., Rynn, M., Wohleberg, C., Greenbaum, M. S., Childress, A., et al. (2003). Efficacy of sertraline in the treatment of children and adolescents with major depressive disorder: Two randomized controlled trials. Journal of the American Medical Association, 290, 1033-1093.

Whittington, C. J., Kendall, T., Fonagy, P., Cottrell, D., Cotgrove, A., \& Boddington, E. (2004). Selective serotonin reuptake inhibitors in childhood depression: Systematic review of published versus unpublished data. The Lancet, 363, 1341-1345.

Zuckoff, M. (2000, June 8). Prozac data was kept from trial, suit says. The Boston Globe, p. 1.

Offprints. Requests for offprints should be directed to Jonathan Leo, $\mathrm{PhD}, 17607$ White Tail Court, Parrish, FL 34219. E-mail: jleo1@tampabay.rr.com 
04_EHPP_8(1)_leo.qxd 1/27/06 3:08 PM Page 42 